\title{
Effect of egg yolk and other reagents upon the zinc of cold-shocked boar spermatozoa*
}

\author{
J. C. Boursnell $\uparrow$, P. Niemczuk and K. I. von Glos \\ A.R.C. Institute of Animal Physiology, Animal Research Station, \\ 307 Huntingdon Road, Cambridge CB3 OJQ, U.K.
}

\begin{abstract}
Summary. A marked reduction $(80.8 \%)$ in the zinc uptake by boar spermatozoa cooled to $4^{\circ} \mathrm{C}$ occurs when the seminal plasma is pretreated with egg yolk-glucose at this temperature. Crude lecithin is less effective $(59.8 \%)$. Similar pretreatment of the seminal plasma by the polycationic drug Antrypol, which totally removes the zinc-precipitable basic haemagglutinin, does not result in a significant reduction of the sperm zinc uptake at $4^{\circ} \mathrm{C}$.
\end{abstract}

\section{Introduction}

The constant ratio of the zinc content of boar spermatozoa cooled to $4^{\circ} \mathrm{C}$ compared with that at room temperature (Boursnell, Partridge \& von Glos, 1977) suggested that a specific temperature-sensitive receptor may be present on the ejaculated spermatozoa and led to the present study of the effect upon sperm zinc at $4^{\circ} \mathrm{C}$ of substances known to protect spermatozoa against damage caused by cold shock. The substances used were egg yolk, a well known protective agent for spermatozoa against cold-shock damage (Phillips, 1939; Anderson, 1944; Pursel \& Johnson, 1975), and lecithin (phosphatidyl choline), a component of egg yolk (Parkinson, 1966), which has also been used as a protective agent (Butler \& Roberts, 1975).

The possible involvement of the cationic haemagglutinin present in boar seminal plasma (Boursnell, 1967; Boursnell \& Briggs, 1969) was also explored, particularly as it appeared to be capable of binding zinc (Boursnell, Noble \& Andrews, 1975). A potent colourless and neutral polyanionic reagent, Antrypol, was used to remove completely the haemagglutinin from the seminal plasma.

\section{Materials and General Methods}

Fresh whole boar semen was collected from mature boars housed at the Animal Research Station and strained through a large nylon sieve to remove the gel before immediate use. Egg yolks were obtained from fresh chicken eggs and each was mixed with $100 \mathrm{ml} 3 \cdot 2 \%(\mathrm{w} / \mathrm{v})$ glucose. For some experiments (see 'Results'), the mixture was buffered with $10 \mathrm{~mm}$-imidazole and the $\mathrm{pH}$ was adjusted to 7.5. Lecithin (egg, crude) was obtained from BDH Chemicals Ltd.

Antrypol (I.C.I. Ltd) is a synthetic trypanocidal drug of molecular weight 1428 (see Town, Wills \& Wormall, 1949), and has been referred to as Bayer 205, Germanin and Suramin. It is known to precipitate basic histones and protamines (Mandel \& Steudel, 1926).

The methods for centrifugation and zinc determination were those described by Boursnell et al. (1977) and Boursnell \& Mustill (1975) respectively. Zinc determinations on egg yolk, lecithin and Antrypol precipitates from seminal plasma were carried out after solubilization in $1 \mathrm{M}$-acetic acid. Haemagglutinin was tested as described by Roberts \& Boursnell (1974).

A micro-Kjeldahl method was employed for protein nitrogen determinations and the ammonia was estimated as described by Boursnell, Hartree \& Briggs (1970).

Calculation of reagent effectiveness. The reduction from the $4^{\circ} \mathrm{C}$ control sperm zinc value produced by the reagents was normally expressed as a percentage of the difference between the control sperm zinc values at $4^{\circ} \mathrm{C}$ and room temperature $\left(19-22^{\circ} \mathrm{C}\right)$. When extra zinc was added the difference be-

* Reprint requests to Dr K.I. von Glos.

$\uparrow$ Deceased. 
tween the zinc value of treated spermatozoa at $4^{\circ} \mathrm{C}$ and room temperature was expressed as a percentage of the difference between the control values at these temperatures.

Various methods were tested to separate the treated spermatozoa from the seminal plasma. The use of diethyl- and dibutyl-phthalate mixtures giving different densities (Lavon, Volcani, Amir \& Danon, 1966) and of Ficoll (Beatty, 1964) gave satisfactory separations of spermatozoa from seminal plasma in untreated semen, but failed when whole semen aliquots were initially treated with egg yolk or lecithin. Microscopical examination revealed that many spermatozoa remained trapped in the voluminous centrifuged precipitate mat. No satisfactory means was found to separate these trapped spermatozoa. All semen was therefore initially centrifuged for separate treatment of the seminal plasma by the reagent. Only the supernatant, centrifuged from the precipitate caused by this treatment, was returned to the spermatozoa.

Zinc in egg yolk-glucose, lecithin and Antrypol. Zinc determinations showed that the total $\mu \mathrm{g}$ zinc contributed in the $0.2 \mathrm{ml}$ volumes of these reagents applied to the seminal plasma samples was very small: egg yolk-glucose, $0.5 \mu \mathrm{g}$; lecithin, $0.1 \mu \mathrm{g}$; Antrypol, <0.03 $\mu \mathrm{g} \mathrm{Zn}$.

\section{Detailed Methods and Results}

\section{Exp. I: egg yolk pretreatment}

Samples $(1.0 \mathrm{ml})$ of fresh boar semen were dispensed into polypropylene tubes and centrifuged. The supernatant plasma samples from triplicate sets were transferred to clean centrifuge tubes and to these tubes $0.2 \mathrm{ml}$ volumes of an egg yolk-glucose-imidazole mixture ( $\mathrm{pH} \mathrm{7.5)}$ were added. One set was cooled to $4^{\circ} \mathrm{C}$ and the other retained at room temperature. After $15 \mathrm{~min}$ the precipitates from the egg yolk-treated samples were centrifuged and the supernatant fluids returned to their respective spermatozoa which were thoroughly resuspended in these fluids. The samples of semen thus treated were cooled to $4^{\circ} \mathrm{C}$ or kept at room temperature according to the previous temperature treatment of their supernatants. After 30 min the samples were centrifuged and the seminal plasma supernatant fluids separated. At the same time, control experiments were carried out with unbuffered egg yolk in glucose (at pH 6.85) and with semen at $4^{\circ} \mathrm{C}$ and room temperature without egg yolk treatment.

The results of this experiment are shown in Table 1 . The reductions (calculated as described) from the $4^{\circ} \mathrm{C}$ control sperm zinc value were 80.7 and $75.2 \%$ for the buffered egg yolk respectively. The mean percentage reduction obtained from 13 comparable experiments is given in Table 2.

\section{Exp. II: lecithin pr. treatment}

Seven experiments were carried out as above but with crude lecithin instead of egg yolk. Table 1 shows one of these experiments in which a final concentration of $1.67 \mathrm{~mm}$-lecithin was used, and which also compares the effect of unbuffered egg yolk. In this experiment the percentage reductions from the $4{ }^{\circ} \mathrm{C}$ control sperm zinc value were : $43.3 \%$ for lecithin and $96.7 \%$ for egg yolk.

Usually a final concentration of $1.67 \mathrm{~mm}$-lecithin was employed but the reduction percentage was not affected by concentrations of $1,2,3$ or 4 mm-lecithin. The mean percentage reduction obtained from 10 comparable experiments is given in Table 2.

\section{Exp. III: egg yolk $+Z n$ pretreatment}

The methods were similar to those of Exp. I for unbuffered egg yolk, but included two extra sets of tubes to which an amount of zinc (as described below) was added to (1) the seminal plasma and (2) the supernatant obtained from the egg yolk treatment of the seminal plasma. The zinc was applied as zinc acetate in $6.6 \mathrm{~mm}$-tri-sodium citrate-10 mM-imidazole at $\mathrm{pH} 7.0$ to give a final zinc concentration of $77 \%$ of that measured initially in the seminal plasma (see subscript, Table 2).

The results of this experiment are given in Table 1. Four other experiments were similarly carried out. The mean ( \pm s.d.) values found in the 5 experiments in Exp. III with fresh semen samples obtained from 4 boars, were $2 \cdot 15 \pm 0.46$ for the control $4^{\circ} \mathrm{C}$ to room temperature ratio, and $87.0 \pm 19 \cdot 3$ for the percentage reduction due to the egg yolk. The mean $4^{\circ} \mathrm{C}$ minus room temperature differences in the 


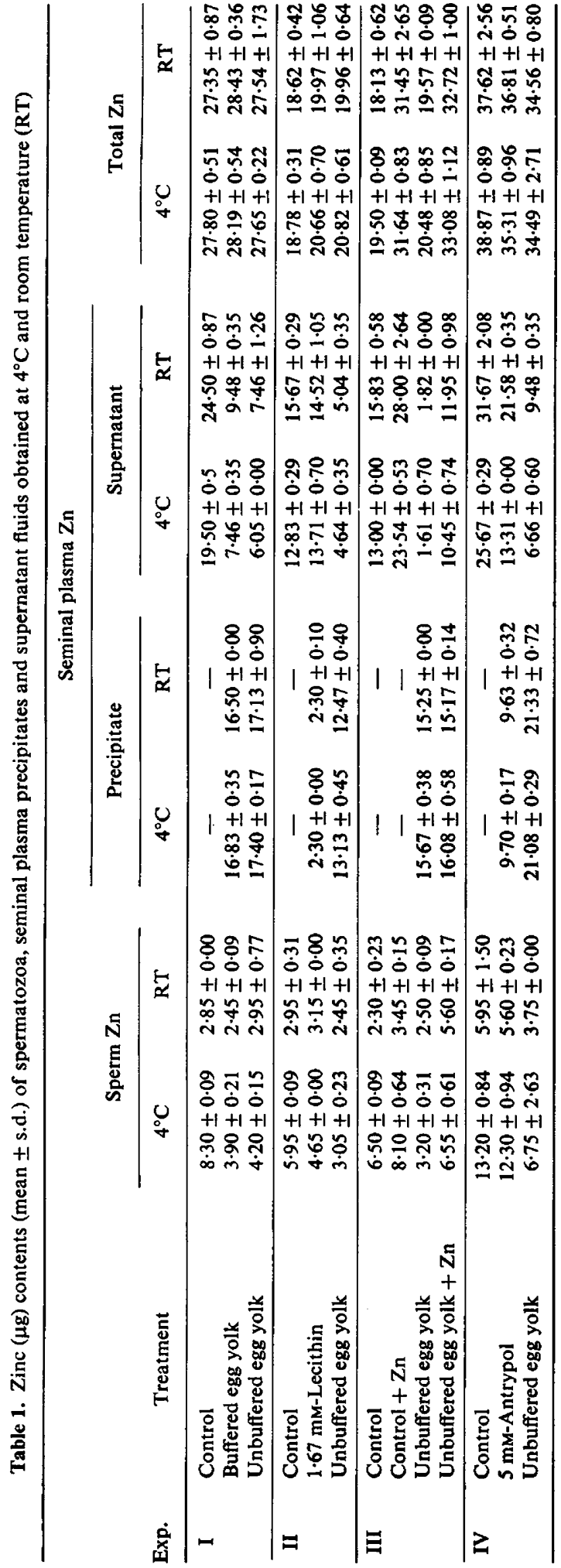


Table 2. Comparative mean ( \pm s.d.) percentage reductions in sperm zinc at $4^{\circ} \mathrm{C}$ caused by egg yolk, lecithin and Antrypol pretreatments of boar seminal plasma

\begin{tabular}{|c|c|c|c|c|c|}
\hline \multirow[b]{2}{*}{ Treatment } & \multirow[b]{2}{*}{$\begin{array}{l}\text { Mean \% reduction } \\
\text { in } 4^{\circ} \mathrm{C} \text { sperm zinc }\end{array}$} & \multirow{2}{*}{$\begin{array}{l}\text { Mean } \% \text { seminal } \\
\text { plasma zinc } \\
\text { remaining in } \\
\text { supernatant } \\
\text { after treatment } \neq\end{array}$} & \multirow{2}{*}{$\begin{array}{c}\text { Mean } 4^{\circ} \mathrm{C}: \text { room } \\
\text { temperature } \\
\text { sperm zinc } \\
\text { ratio }\end{array}$} & \multicolumn{2}{|c|}{ Number of: } \\
\hline & & & & $\begin{array}{l}\text { Experimental } \\
\text { values }\end{array}$ & Animals \\
\hline \multicolumn{6}{|l|}{ Egg-yolk } \\
\hline+ glucose & $80 \cdot 8 \pm 16 \cdot 4$ & $29.0 \pm 5.9$ & $2.39 \pm 0.37$ & 13 & 5 \\
\hline Lecithint & $59.8 \pm 13.0$ & $91 \cdot 1 \pm 6 \cdot 6$ & $2.46 \pm 0.27$ & 10 & 5 \\
\hline $\begin{array}{l}\text { Antrypol } \\
(0.83 \mathrm{~mm}\end{array}$ & & & & & \\
\hline final conc.) & $6.4 \pm 7.4$ & $67 \cdot 1 \pm 5 \cdot 8$ & $2.47 \pm 0.37$ & 4 & 3 \\
\hline
\end{tabular}

* Relative to control $4^{\circ} \mathrm{C}$ and room temperature values: $100 \times\left(4^{\circ} \mathrm{C}\right.$ control $-4^{\circ} \mathrm{C}$ experimental $) /\left(4^{\circ} \mathrm{C}\right.$ control room temperature control).

+ Includes one experiment investigating the effect of 1-4 mM-lecithin final concentration. The results were not significantly different from those with $1.67 \mathrm{~mm}$ (final conc.).

$\ddagger$ The corresponding observed values for the mean $\%$ zinc in the precipitates are: egg yolk, $77 \cdot 2 \pm 8 \cdot 7 ;$ lecithin, $9 \cdot 3 \pm 3 \cdot 8 ;$ Antrypol, $28 \cdot 9 \pm 1 \cdot 3$.

treated sperm zinc values, expressed as a percentage of the corresponding control differences, were 12.6 and $27.2 \%$ in the samples treated with egg yolk and egg yolk + zinc respectively.

\section{Exp. IV: effect of Antrypol on haemagglutinin and nitrogen}

Duplicate sets $(0.6 \mathrm{ml})$ of a frozen boar seminal plasma were dispensed into centrifuge tubes and treated with $20 \mu$ l of dilutions of an Antrypol solution in saline to give a wide range of final Antrypol concentrations. After $1 \mathrm{~h}$, the tubes were centrifuged and the haemagglutinin titres of the supernatant fluids from one set were determined. The precipitates obtained from this set were used for the total nitrogen determinations. The other set was used to provide samples of the supernatant fluids for treatment with $30 \mu \mathrm{l}$ of a solution of zinc citrate, buffered to $\mathrm{pH} 7$ with imidazole, to give a final zinc concentration of $5.7 \mathrm{~mm}$. After $2 \mathrm{~h}$ at room temperature, these tubes were centrifuged and the precipitates were used for total nitrogen determinations. A second confirmatory experiment on the same seminal plasma employed a narrower range of Antrypol concentrations, but was otherwise identical.

The combined results of these two experiments are given in Text-fig. 1.

A third experiment with fresh seminal plasma obtained from another boar confirmed these results.

\section{Exp. V: comparative effects on haemagglutinin}

Three samples of fresh seminal plasma obtained from 3 boars were each titrated in duplicate, against sheep red cells, after treatments with (1) egg yolk-glucose or (2) $0.83 \mathrm{~mm}$ final concentrations of Antrypol. The results showed that, while the Antrypol treatments completely eliminated the haemagglutinin activity, the egg yolk only reduced the mean titre $(12.7$ wells \pm 1.4 s.d.) by 4.7 wells ( \pm 1.4 s.d.).

Similar treatments of three other samples of seminal plasma, from 3 boars, with $1.67 \mathrm{~mm}$ final concentrations of lecithin only reduced the mean titre $(10.3$ wells $\pm 1 \cdot 2$ s.d.) by one well in all cases. In control tests lacking seminal plasma, minor agglutination ( $3 \cdot 3$ wells $\pm 0 \cdot 6$ s.d.) occurred only with egg yolk.

\section{Exp. VI: Antrypol pretreatment}

In 4 experiments, with fresh semen from 3 boars and following the procedures described earlier for the egg yolk and lecithin experiments, the effects of Antrypol were explored.

When final replicate Antrypol concentrations of $0.083 \mathrm{~mm}$ and $0.83 \mathrm{~mm}$ were compared with those of an untreated semen control, the percentage reductions from the $4^{\circ} \mathrm{C}$ sperm zinc control value were very small $(5.6 \%$ and $0 \%$ respectively). 


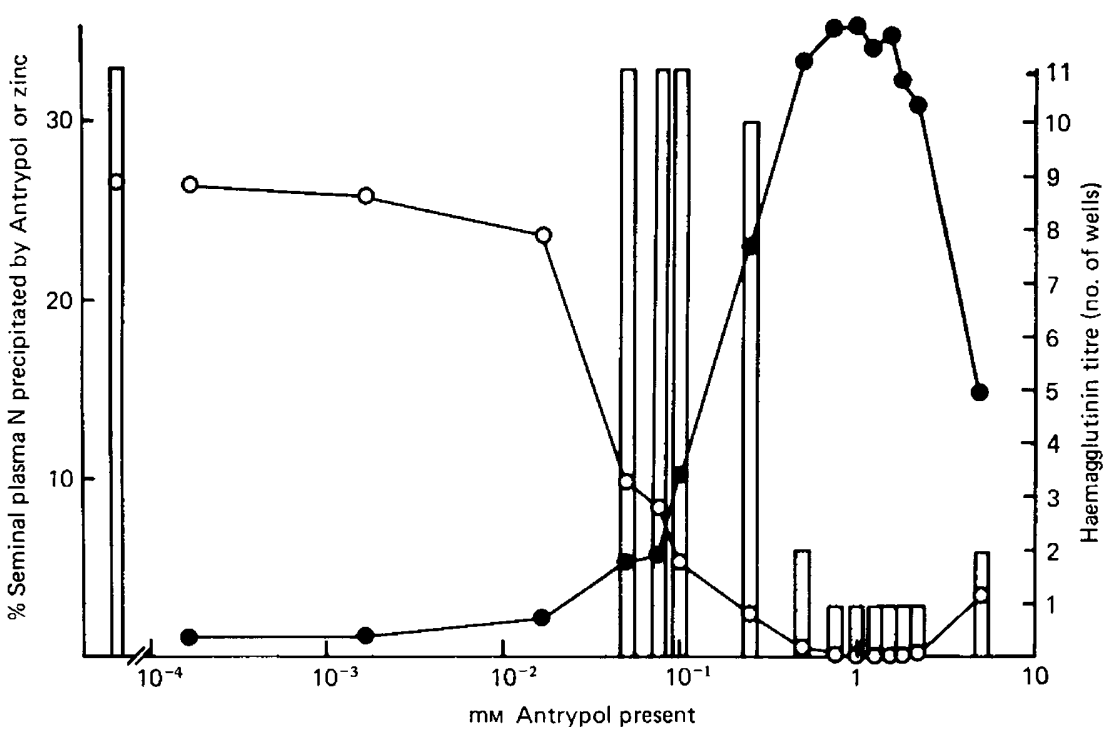

Text-fig. 1. The combined results of two of the three experiments in Exp. IV showing the change in total nitrogen, expressed as \% of that in untreated seminal plasma, in precipitates obtained by treatment of boar seminal plasma with Antrypol (•), and in precipitates obtained by treatment of the Antrypol supernatant fluids with $5.7 \mathrm{~mm}$ buffered zinc citrate $(O)$. The histograms show the haemagglutinin titres of the supernatant fluids after the Antrypol treatment without added zinc.

In the other 3 experiments the effect of Antrypol ( $0.83 \mathrm{~mm}$ final concentration) was compared with that of unbuffered egg yolk and the results of one of these experiments are shown in Table 1 . This experiment revealed a much smaller percentage reduction with the Antrypol $(12.4 \%)$ than with the egg yolk $(89.0 \%)$. The mean percentage reduction found in the experiments with final concentrations of $0.83 \mathrm{~mm}$ Antrypol is given in Table 2.

\section{Discussion}

As suggested in the 'Introduction', the higher $(\times 2 \cdot 3)$ zinc content of boar spermatozoa that have been cold-shocked compared with uncooled spermatozoa may represent a specific receptor on the sperm surface. This extra uptake of zinc at $4^{\circ} \mathrm{C}$ has now been shown to be markedly reduced by the application of egg yolk. The effect of this known protective agent reinforces the idea that the zinc receptor on boar spermatozoa may play an important role in sperm damage.

Comparisons between the action of egg yolk and crude lecithin show that the former is more effective than the latter in reducing the zinc in the cooled spermatozoa. The work reported here does not set out to establish that it is necessarily the lecithin (phosphatidyl choline) contained in the egg yolk (Parkinson, 1966) which confers the protective properties. Evidence is, in fact, accumulating that other phospholipids may be more effective (Butler \& Roberts, 1975). Lecithin is insoluble in aqueous solution and forms an unstable suspension which partly precipitates unless vigorously stirred. It is possible that the greater physicochemical stability of phospholipids in egg yolk, promoted by their presence as lipoprotein complexes (Chargaff, 1942), may enhance the efficacy of egg yolk as a protective agent against cold-shock.

The use of the colourless and neutral Antrypol, containing two 1-naphthylamine trisulphonic acid groups, was suggested by earlier observations (Nelson \& Boursnell, 1966; Boursnell, 1967) that dextran sulphate, heparin and other strongly polyacidic substances inhibited the haemagglutinin titration of boar seminal plasma. The complete precipitation by Antrypol of the basic haemagglutinin is in apparent contrast to its combination in vivo with the more acidic blood plasma proteins which it does 
not precipitate (Boursnell \& Wormall, 1939). In addition, the action of Antrypol shown in Text-fig. 1 gives added support to the apparent identity of the haemagglutinin and the zinc-precipitable protein shown by Roberts, Boursnell \& Brown (1974) and Boursnell et al. (1975). It is clear that the complete elimination of the haemagglutinating zinc-precipitable protein from the seminal plasma by the use of Antrypol makes virtually no difference to the $4^{\circ} \mathrm{C}$ to room temperature sperm zinc ratio. The partial reduction of the seminal plasma haemagglutinin by egg yolk (and lecithin) shown in this work therefore has little or no connection with the protective action against sperm damage during cooling. The effects observed could be due partly to the centrifugation procedure or entirely to temperature. However, our present and previous results show that the 2.3 zinc ratio is maintained during the use of various centrifugation procedures.

The marked loss of zinc (mean, $77 \%$ ) from the seminal plasma to the egg-yolk precipitate is also an unlikely cause of the $4^{\circ} \mathrm{C}$ sperm zinc reduction. Replacement of the 'lost' zinc only affects the percentage reduction to a small extent. The results given by lecithin also suggest that the loss of seminal plasma zinc to the precipitate is not the cause of the considerable lowering of the $4^{\circ} \mathrm{C}$ sperm-zinc value due to egg yolk treatment. Table 2 shows that, with lecithin, $91.1 \%$ of the seminal plasma zinc remains in the supernatant after treatment, yet the percentage reduction of the $4^{\circ} \mathrm{C}$ sperm zinc is still $59.8 \%$.

We are particularly grateful to Miss A. Semere for the many haemagglutinin titrations recorded here, and to Miss M. G. Andrews for the work depicted in Text-fig. 1 ; to Mr K. Elsome, Mr J. Doggett and Mr R. Simons for the collections of boar semen and sheep blood; and to Mr G. V. Short of the Veterinary Services Division, I.C.I. Ltd, Macclesfield, Cheshire, for the gift of Antrypol.

\section{References}

ANDERson, J. (1944) The Semen of Animals and its Use for Artificial Insemination. Imperial Bureau of Animal Breeding and Genetics, Technical Communication.

BeATTY, R.A. (1964) Density gradient media for mammalian spermatozoa. Proc. 5th Int. Congr. Anim. Reprod. \& A.I., Trento, Vol. 3, pp. 276-281.

BourSNELL, J.C. (1967) Boar seminal haemagglutinin. 2. Combination with red cells and spermatozoa. $J$. Reprod. Fert. 13, 297-314.

Boursnell, J.C. \& Briggs, P.A. (1969) Boar seminal plasma proteins. 2. Electrophoretic identification of the haemagglutinin. J. Reprod. Fert. 19, 157-166.

Boursnell, J.C. \& Mustill, E.A. (1975) The absorption of boar seminal zinc by cooled spermatozoa. $J$. Reprod. Fert. 43, 153-157.

Boursnelk, J.C. \& Wormall, A. (1939) Studies on Bayer 205 (Germanin) and Antrypol. 4. The retention of the drug in the animal body. Biochem. J. 33, 11911200.

Boursnell, J.C., Hartree, E.F. \& Briggs, P.A. (1970) Studies of the bulbo-urethral (Cowper's)-gland mucin and seminal gel of the boar. Biochem.J. 117, 981-988.

Boursnell, J.C., Noble, E.A. \& ANdrews, M.G. (1975) Boar seminal zinc-precipitable protein and the haemagglutinin. J. Reprod. Fert. 45, 415-420.

Boursnele, J.C., Partridge, D.R. \& Von Glos, K.I. (1977) The constant ratio of the zinc content of boar spermatozoa at $4^{\circ} \mathrm{C}$ and room temperature. $J$. Reprod. Fert. 49, 391-393.

Butler, W.J. \& Roberts, T.K. (1975) Effects of some phosphatidyl compounds on boar spermatozoa following cold shock of slow cooling. J. Reprod. Fert. 43, 183-187.

Chargaff, E. (1942) A study of lipoproteins. J. biol. Chem. 142, 491-504.

Lavon, U., Volcani, R., Amir, D. \& Danon, D. (1966) The specific gravity of bull spermatozoa and seminal plasma. J. Reprod. Fert. 11, 447-449.

MANdel, J.A. \& STeudel, H. (1926) Über den Wirkungsmechanismus chemotherapeutischer Mittel. HoppeSeyler's Z. physiol. Chem. 160, 91-95.

Nelson, M. \& Boursnell, J.C. (1966) Studies on boar seminal plasma proteins. 4. Isolation of factors with haemagglutinating and protein-precipitating activity. Biochim. biophys. Acta 117, 144-156.

PARKINSON, T.L. (1966) The chemical composition of eggs. J. Sci. Fd Agric. 17, 101-111.

Phill,IPS, P.H. (1939) Preservation of bull semen. J. biol. Chem. 130, 415.

Pursel, V.G. \& Johnson, L.A. (1975) Freezing of boar spermatozoa: fertilizing capacity with concentrated semen and a new thawing procedure.J. Anim. Sci.40, 99-102.

RoBerTS, T.K. \& BoursNell, J.C. (1974) The inhibitory action of phosphatidyl compounds on boar seminal haemagglutinin. J. Reprod. Fert. 41, 489-492.

RobertS, T.K., Boursnell, J.C. \& Brown, A.D. (1974) The rôle of zinc in promoting the opalescence and cold precipitation of boar seminal plasma. 2. Relationship of a zinc-precipitable protein with the haemagglutinin. J. Reprod. Fert. 37, 373-386.

Town, B.W., Wills, E.D. \& Wormall, A. (1949) Action of Suramin on enzymes. Nature, Lond. 163, 735. 